Keywords:

Retention: Permanent

\title{
THE CHEMICAL AND RADIATION RESISTANCE OF POL YPHENYLENE SULFIDE AS ENCOUNTERED IN THE MODULAR CAUSTIC SIDE SOLVENT EXTRACTION PROCESSES
}

\author{
F. F. Fondeur \\ D. T. Herman \\ M. R. Poirier \\ S. D. Fink
}

June 30, 2011

Savannah River National Laboratory

Savannah River Nuclear Solutions

Aiken, SC 29808

Prepared for the U.S. Department of Energy under contract number DE-AC09-08SR22470.

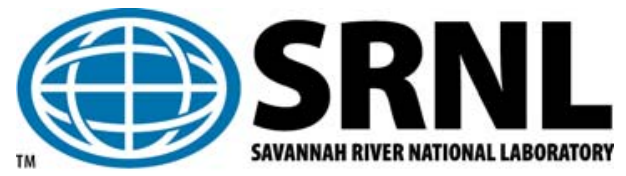


SRNL-STI-2011-00390

Revision 0

\section{DISCLAIMER}

This work was prepared under an agreement with and funded by the U.S. Government. Neither the U.S. Government or its employees, nor any of its contractors, subcontractors or their employees, makes any express or implied:

1. warranty or assumes any legal liability for the accuracy, completeness, or for the use or results of such use of any information, product, or process disclosed; or

2. representation that such use or results of such use would not infringe privately owned rights; or

3. endorsement or recommendation of any specifically identified commercial product, process, or service.

Any views and opinions of authors expressed in this work do not necessarily state or reflect those of the United States Government, or its contractors, or subcontractors.

\section{Printed in the United States of America \\ Prepared for \\ U.S. Department of Energy}




\section{REVIEWS AND APPROVALS}

AUTHORS:

F. F. Fondeur, Separations \& Actinide Science Programs

Date

D. T. Herman, Advance Characterization \& Process

Date

M. R. Poirier, Advance Characterization \& Process

Date

TECHNICAL REVIEW:

T. B. Peters, Separations \& Actinide Science Programs

Date

APPROVAL:

S. D. Fink, Manager

Date

Separations \& Actinide Science Programs

Date

S. L. Marra, Manager

Environmental \& Chemical Process Technology Research Programs

B. A. Oard, Manager

Date

MCU Life Extension Project, SRR Engineering 


\section{EXECUTIVE SUMMARY}

Polyphenylene sulfide (PPS) is extremely resistant to gamma irradiation, caustic solution, and dilute nitric acid. PPS is the material of construction for the coalescers used in the Modular Caustic-Side Solvent Extraction Unit (MCU). After applying the equivalent of 3.3 E8 rad (330 Mrad), or the equivalent of 11 years of gamma irradiation (assuming a stripping solution concentration of $7.5 \mathrm{Ci} / \mathrm{gal}$ ), and several months of exposures to 3M caustic solution and caustic salt simulant, no dimensional changes nor chemical changes were detected in PPS whether the PPS was in fiber form or in a composite with E-glass fibers.

However, PPS acts as a media for heterogeneous nucleation. In particular, PPS appears to favor aluminosilicate formation in saturated solutions of aluminum and silicon in caustic environments.

Parallel testing, in progress, is examining the stability of PPS when exposed to the new solvent formulation under development for MCU. Preliminary data, after two months of exposure, demonstrates PPS is stable to the new solvent. 


\section{TABLE OF CONTENTS}

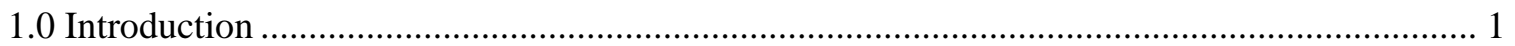

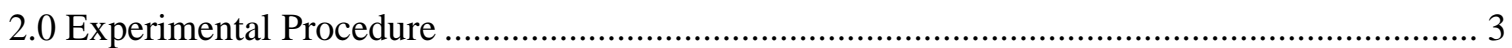

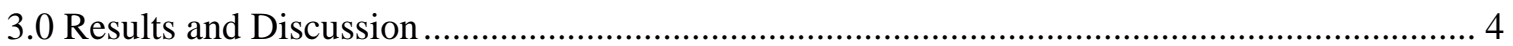

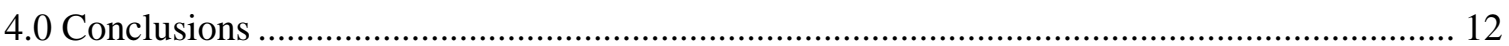

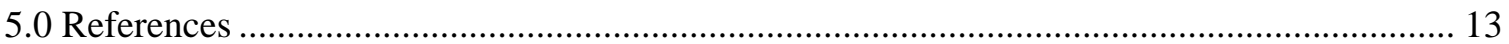


SRNL-STI-2011-00390

Revision 0

\subsection{Introduction}

Polyphenylene sulfide (PPS) is a semicrystalline polymer with excellent engineering plastic properties and suitable processing temperatures. ${ }^{1}$ PPS can also be made containing branches (using a trifunctional monomer) and with crosslinked microstructure (when curing the monomer at high temperature in the presence of oxygen).

PPS is made from the condensation reaction between para-dichlorobenzene and sodium sulfide with the assistance of a catalyst (to lower the activation barrier). The synthesis conditions for making PPS has evolved since its invention in the 1960's to the optimal conditions developed by the Philips Corporation in the 1970's. ${ }^{2}$ The resulting polymer consists of chemically stable molecular moieties such as benzene rings and ether like sulfur linkages between the aromatic rings (as shown below).

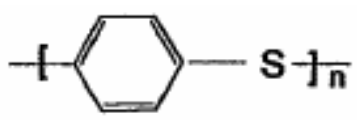

The resulting PPS polymer is a thermoplastic with a sharp melting temperature around $275{ }^{\circ} \mathrm{C}$ that varies (slightly) depending on the polymer processing or aging or storage conditions. The glass transition ranges from 87 (amorphous) to $93{ }^{\circ} \mathrm{C}$ (crystalline) giving this polymer a wide temperature range for processing. This wide temperature range allows for easy processing of this polymer into different (molded) shapes and figures. The molecule is relatively stiff such that upon cooling from the melt this polymer has the tendency to readily crystallize. To minimize crystallization at a practical cooling rate, small amount of additives (or trifunctional monomers) are added to screen the interchain interactions. A common additive is diphenyl disulfide.

Combinations of quenching rate, temperature, and aging at temperature allows the polymer to have a controlled degree of crystallinity that in turn "tunes in" the bulk mechanical properties of this polymer. Annealing post quenched PPS reduces residual stresses (from quenching) and nucleates small lamellas throughout the polymer to give the polymer higher tensile, compressive and bending strength as well as toughness (exhibited as an ability to arrest internal crack propagation). Blending PPS with fillers (i.e., glass or carbon fibers) is another way to improve the strength of the polymer (via an increase in the glass transition of the polymer for example). An excellent review of the mechanical properties of PPS that includes impact strength (toughness), fatigue, viscoelasticity (creep), and tensile/compressive strength is provided by Spruiell and Janke. ${ }^{3}$

Heating the polymer at high temperature for short times (less than minutes) in the presence of air introduces crosslinking microstructure into the polymer that can enhance the ultimate tensile and compressive strength.

However, heating the polymer beyond $350{ }^{\circ} \mathrm{C}$ in air introduces significant oxidation reactions (as shown in the table below) that can change the polymer mechanical and chemical stability. 
SRNL-STI-2011-00390

Revision 0

Temperature in air $\left({ }^{\circ} \mathrm{C}\right)$

350

380

420

440
Products

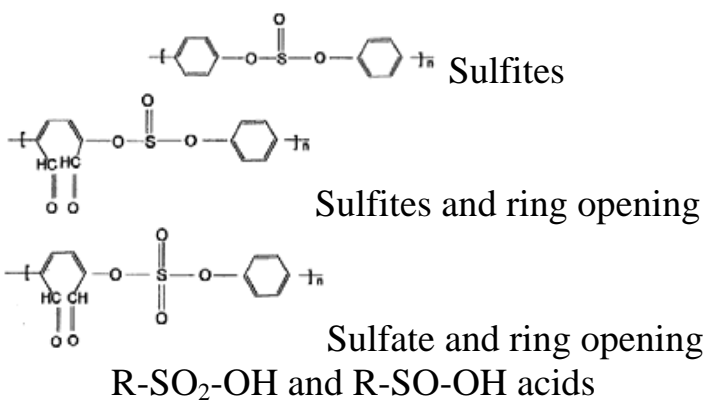

If heating PPS past $300{ }^{\circ} \mathrm{C}$ under a reducing atmosphere, pyrolysis reactions will yield byproducts such as hydrogen, hydrosulfide gases, carbonyl sulfide, carbon monoxide, and a carbonaceous residue.

Previous reviews (such as Reference 3) have not extensively examined the effect of radiation on PPS and the stability of PPS to solutions including organic liquids. In particular, data is scarce on the effect of blending of organics liquids with different polarities (hydrophobic and hydrophilic) on the dimensional stability PPS.

PPS undergoes chemical transformation during irradiation with ion bombardment or gamma irradiation. Ion bombardment (with $\mathrm{Ar}^{2+}$ at $700 \mathrm{keV}$ under vacuum) on PPS revealed chemical bond disruptions and free radical formation (loss of hydrogen atom). ${ }^{4}$ The damage also included additional cross-linking and loss of crystallinity. More beam exposure led to extensive bond conjugation that imparted the PPS with electrical conductivity similar to a semiconductor. The bombardment-induced conductivity disappeared upon exposure to oxygen from air.

A similar chemical degradation was seen when PPS was bombarded with hydrogen ions. ${ }^{5}$ Bombardment with hydrogen led to desulfurization, conjugation formation, and carbonaceous material formation in PPS. These effects (with the exception of carbonaceous materials formation) are similar to laser ablation where a total removal of material occurs. Bombarding PPS with $\mathrm{H}^{+}$and other ions $\left(\mathrm{He}^{+}, \mathrm{C}^{2+}, \mathrm{O}^{3+}, \mathrm{S}^{3+}, \mathrm{Br}^{9+}\right.$ and $\mathrm{I}^{14+}$ ) led to bond breaking and rearrangement similar to $\mathrm{Ar}$ bombardment. The chemical bonds most susceptible to bombardment were C-S and S-S. The aromatic rings in PPS were found to be resistant to ionic bombardment. ${ }^{6}$

Under photonic irradiation such as gamma irradiation, PPS has proven to be resistant with no changes to its mechanical properties (tensile strength and elongation at the breaking strength) to $500 \mathrm{kGy}(50 \mathrm{Mrad})$ or less. ${ }^{7}$ This is attributed in part to the tendency of the ionized electrons (removed from an atom in PPS) to return to the PPS. However, when the dose is larger than 500 kGy, hydrogen and sulfur losses (indicated by the loss in C-H stretch and bend and C-S stretch in the FTIR spectrum) as well as conjugation were observed. ${ }^{8}$

The objective of this work was to investigate the chemical and radiation resistance of PPS in caustic solution and selective organic liquids under gamma irradiation. The data from this work provides the input necessary for using PPS as the polymer media for both filtration and coalescing oil-in-water dispersion. 


\subsection{Experimental Procedure}

To evaluate the chemical and radiation resistance of PPS, two forms of PPS were obtained: 1nonwoven fiber shaped PPS (90\% to 92\% porosity), and 2- E glass-filled PPS coupons. Although E-glass filled PPS coupons are not installed in MCU, we have chosen to evaluate the gamma irradiation resistance of PPS in the E-glass composite form because that configuration packs the most PPS fibers per unit volume (when compared to a non-woven PPS) and the higher the density is the higher is the capture of photons. The E-glass/PPS composite presents a very sensitive configuration to radiation damage that an air-filled non-woven PPS fiber network may not offer.

We obtained several coupons ( $2 \times 2 \times 0.25 \mathrm{~cm}^{3}$ and $5 \times 5 \times 2 \mathrm{~mm}^{3}$ ) of Ryton $4^{\mathrm{TM}}$ samples (PPS) reinforced with E-fiberglass ( $20 \%$ by volume). The coupons were used as received and immersed in salt solution (5.6 M [Na], $1.91 \mathrm{M}[\mathrm{OH}]$ and $\left.0.31 \mathrm{M}^{2} \mathrm{AlO}_{2}^{-}\right]$) with no mixing.

In some cases, coupons were exposed to gamma radiation at a dose rate of $7.11 \mathrm{E} 5 \mathrm{rad} / \mathrm{h}$ (using a J. L. Sheppard model 109 equipped with a Cobalt source) to give the coupons a total dose of 4.95 E8 rad (or the equivalent of 40,000 years of plant service given that $2.5 \mathrm{mCi} / \mathrm{gal}^{*}$ is a typical decontaminated salt solution dose and it is the equivalent of 16 years of service on the stripping process of MCU where solution may contain up to $7.5 \mathrm{Ci} / \mathrm{gal}) .{ }^{9}$ Gamma source temperature and humidity was approximately $35{ }^{\circ} \mathrm{C}$ and $60 \% \mathrm{RH}$ (relative humidity).

Some coupons were exposed to $3 \mathrm{M}$ caustic solutions for different lengths of times. [For simplicity, testing used $3 \mathrm{M} \mathrm{NaOH}$ solutions as opposed to a full simulant of the prototypical waste solution. The $3 \mathrm{M} \mathrm{NaOH}$ is in the high range of the expected free hydroxide concentration for operations. Furthermore, chemical attack is expected to be primarily through attack by the free hydroxide, by free acid during cleaning, or by radiolytic attack involving free radicals.] Other coupons received radiation and caustic exposure simultaneously.

After treatment, samples were analyzed by multiple contacts using ATR-FTIR (attenuated total reflectance - Fourier transform infrared spectroscopy).

Some samples were also analyzed by thermogravimetry analysis (TGA) and differential scanning calorimetry (DSC). TGA is basically a balance placed in an oven where the sample is heated linearly with time while the sample weight is monitored. In this case, the TGA will be used to determine the amount of polymeric material (PPS) that remains in the composite. The DSC measures the temperature of the samples as the sample is heated. In this case, the DSC will be used to monitor the temperature rise in PPS due to oxidation in air. The lower the temperature rise, the less PPS is present relative to the as received E-glass/PPS composite.

PPS fibers were also exposed to caustic (1.91 M [OH]) and dilute nitric acid (1 mM) under gamma irradiation for evaluation.

\footnotetext{
* This is equivalent to $1.1 \mathrm{rem} / \mathrm{hr}$ (quality factor value of 1 ) at the sampling point which is far larger than the measured $2 \mathrm{mrem} / \mathrm{hr}$ measured at the center of the room. Please recall that dose rate inversely decays with the square of distance from the source.
} 


\subsection{Results and Discussion}

\section{E-Glass/PPS Composite}

The effect of gamma irradiation on E-glass/PPS composite is shown in Figure 1. As can be seen from Fig. 1, PPS is very resistant to gamma irradiation until the total radiation accumulated was $4.95 \mathrm{E} 8 \mathrm{rad}$. Further exposure clearly shows the breaking of the aromatic rings (oxidation) and the oxidation of the sulfur atom in PPS. The formation of sulfides and sulfates is clearly seen in Fig. 1. This makes the surface more polar and susceptible to wetting.

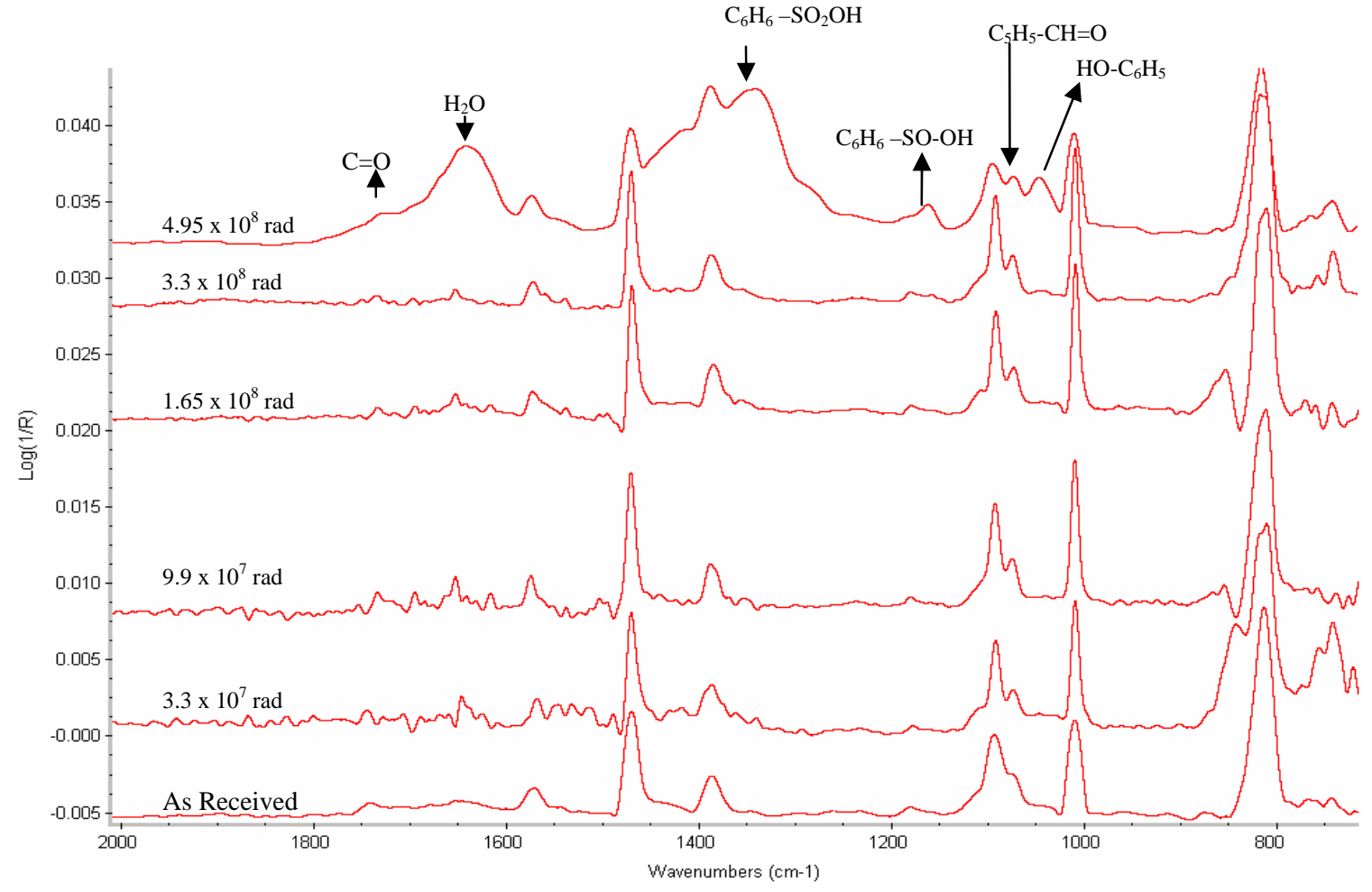

Figure 1. FTIR of the surface of PPS as a function of applied radiation dose (given in rad).

The formation of sulfonic and sulfinic groups on PPS can be summarized in the reaction below.

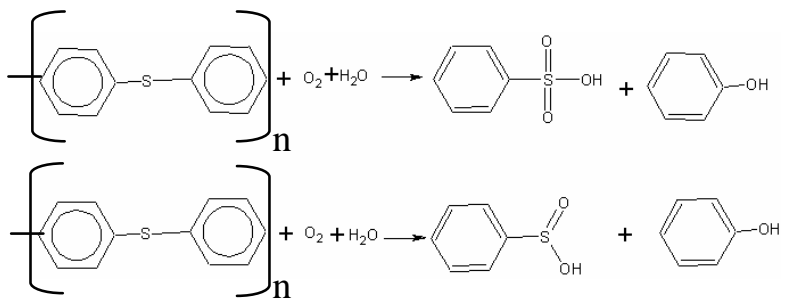

Exposing the E-glass/PPS composite to 4.95 E8 rad (and greater) clearly affected the surface texture of the composite. The surface appeared more smoothed with wider pits as a result of the large irradiation (see Figure 2).

The irradiation also affected the thermal behavior of E-glass/PPS as shown in Figure 3. 


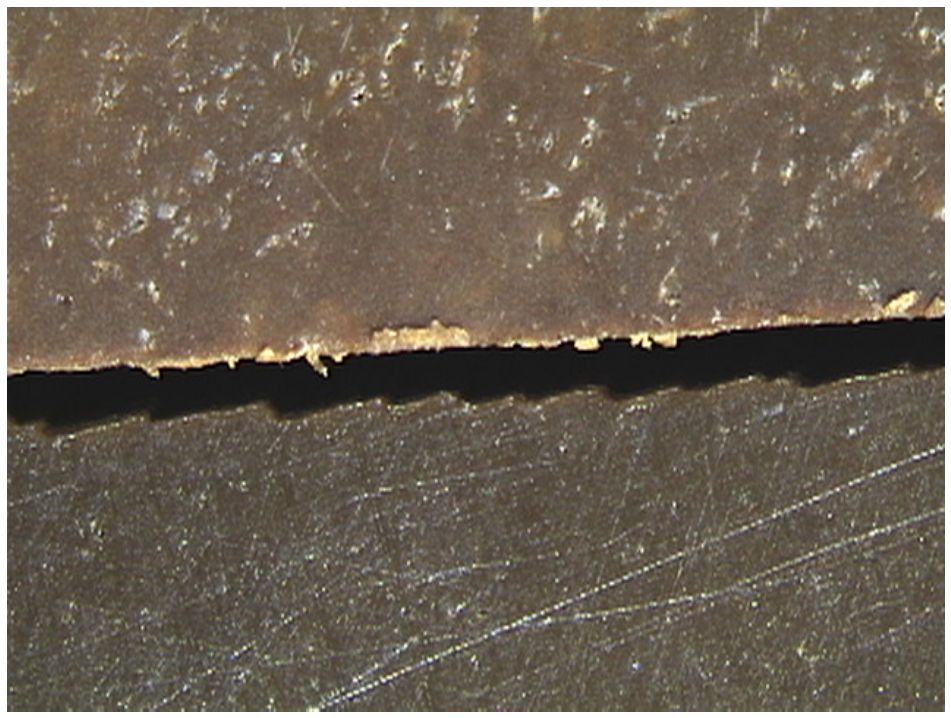

Figure 2. An optical picture (looking on top) of glassreinforced PPS before (bottom) and after gamma
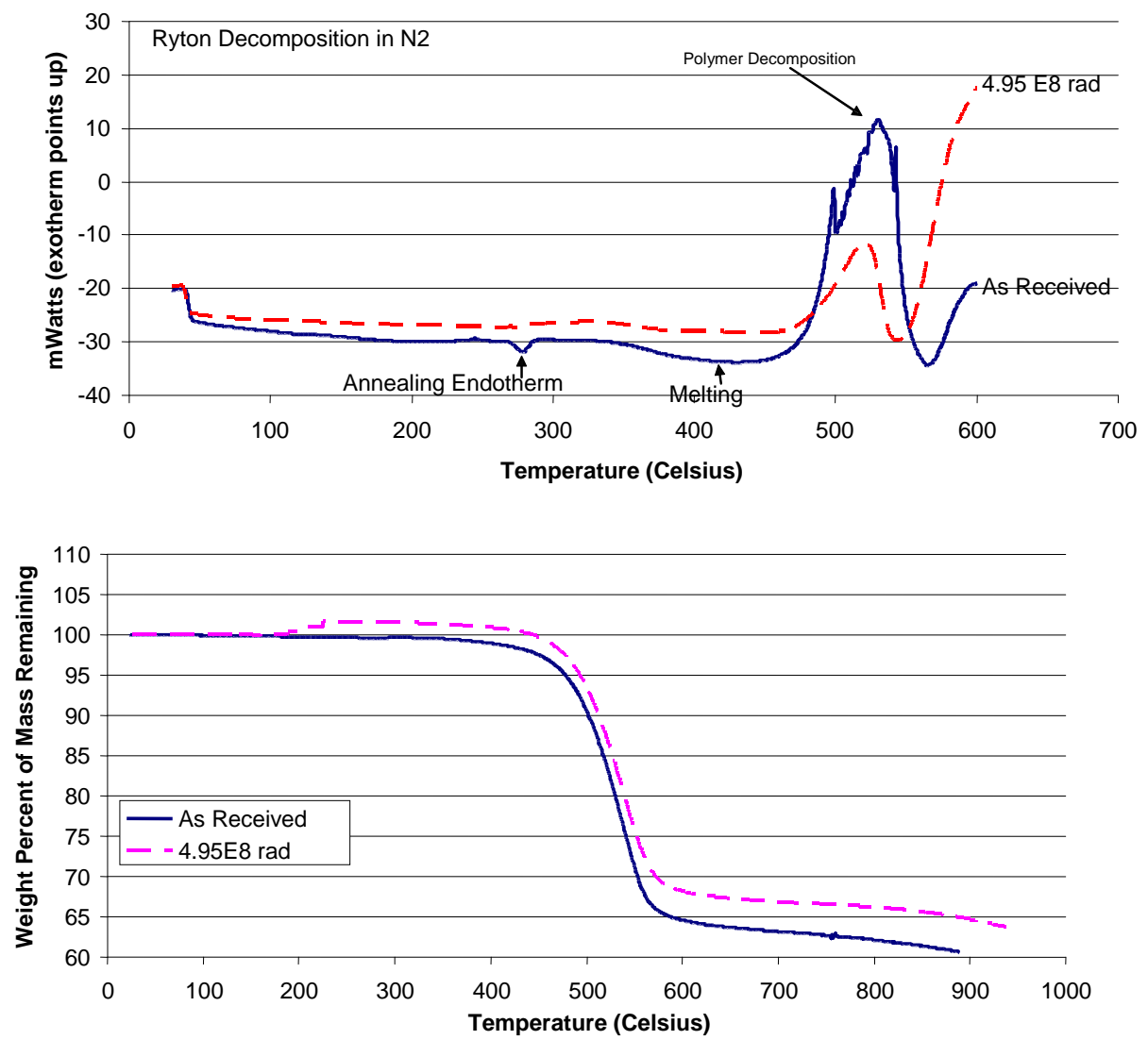

Figure 3. Both the DSC (top) and TGA (bottom) indicate that the gamma irradiation reduced the amount of organic (E-glass/PPS) material at the surface. 
As can be see in Figure 3, the DSC clearly showed less oxidation (reaction with air) occurred in the E-glass/PPS sample that was irradiated since the irradiation process has oxidized the surface leaving less original material for additional oxidation. The TGA data clearly shows that more material volatized off (under nitrogen) in the "as received" composite than in the irradiated Eglass/PPS (36 wt \% loss versus 33 wt \% loss). Note that these changes occurred after the composite was exposed to the equivalent 4.95 E8 rad applied dose.

Exposing the E-glass/PPS composite to caustic salt solution (without radiation) containing aluminum led to the formation of aluminosilicate on the surface of the composite. Figure 4 shows evidence of the formation of aluminosilicate after one month of exposure. The presence of aluminum in solution probably reacted with the silica in E-glass to form the aluminosilicate. The probable mechanism may have included the dissolution and transport of silicon from inside the composite to the surface when it reacted with aluminum to deposit a film of aluminosilicate. Figure 5 shows a picture of E-glass/PPS before and after exposure to caustic clearly showing the presence of a sodium aluminosilicate film on the sample. Note the picture was taken after 5 months of exposure where the film is thick enough to be optically visible.

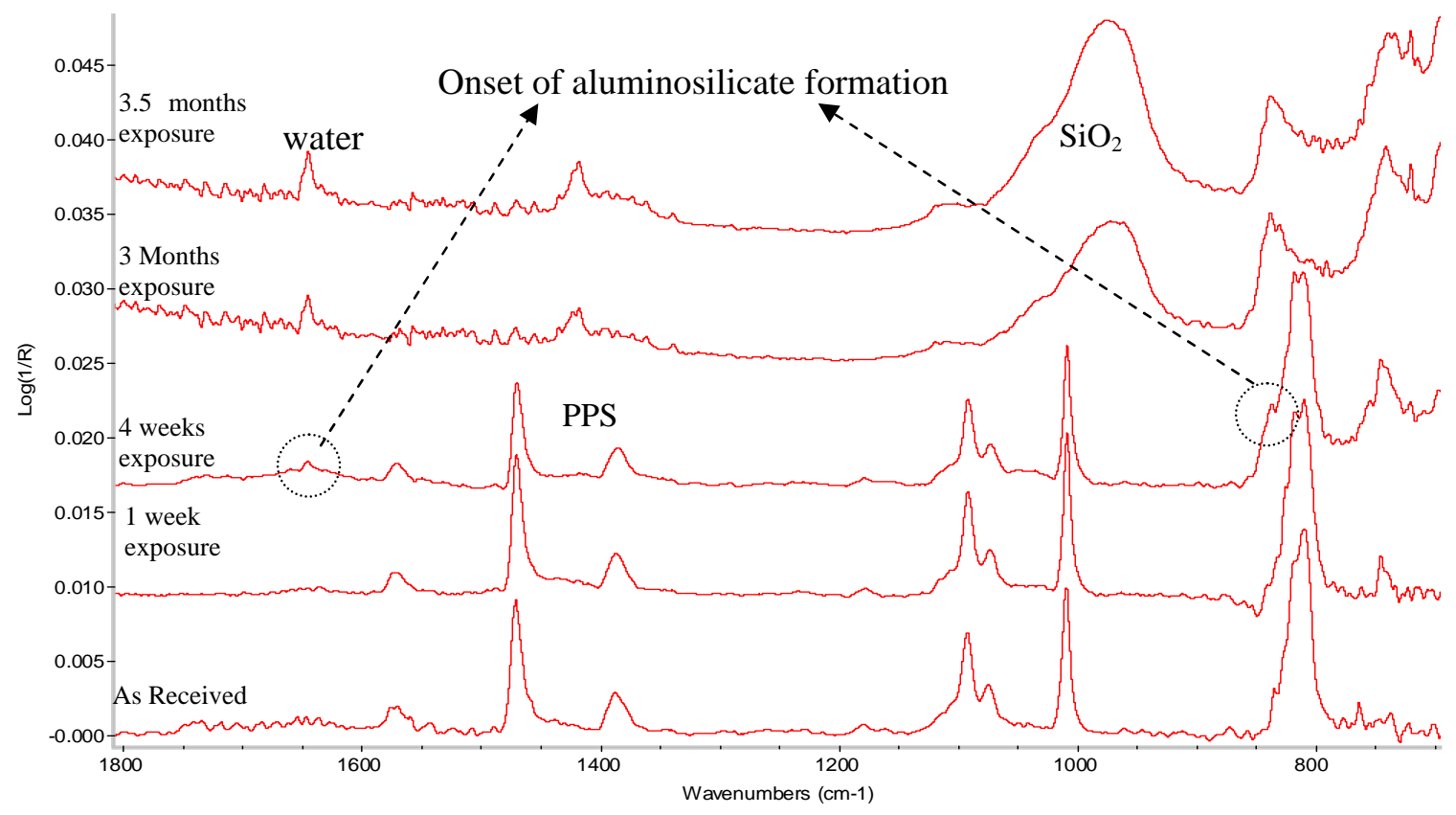

Figure 4. FTIR of the surface of E-glass/PPS after exposure to a 5.6 $\mathrm{M} \mathrm{NaOH}$ solution containing aluminum and silicon (solution mimics a SRS waste composition).

Further evidence of the change in the surface of the E-glass/Ryton composite is shown in Figure 6 where the texture of elongated E-glass fibers disappeared after exposure to a salt solution containing aluminum. Using a microthermal analyzer (which is an atomic force microscope equipped with a thermal probe), changes in both the topography and thermal conductivity of the surface of the composite were observed as a result of the exposure. In this case, the resulting aluminum silicate has a bumpy texture (raised elevations that resemble mountains). 


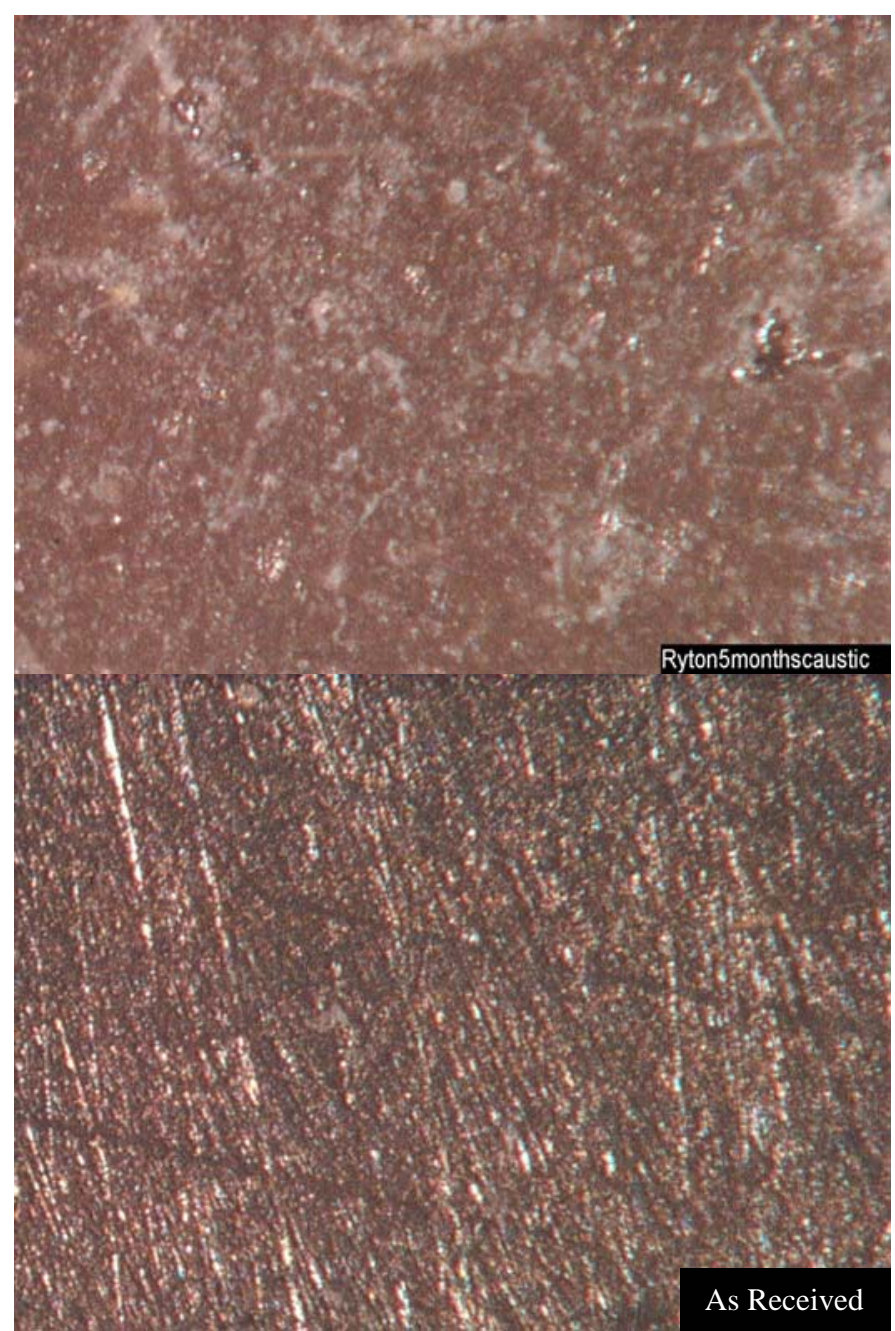

Figure 5. An optical picture of the surface of E-glass/PPS after exposure to a $1.91 \mathrm{M}[\mathrm{OH}]$ solution (top) compared to the same surface before the exposure (bottom). 


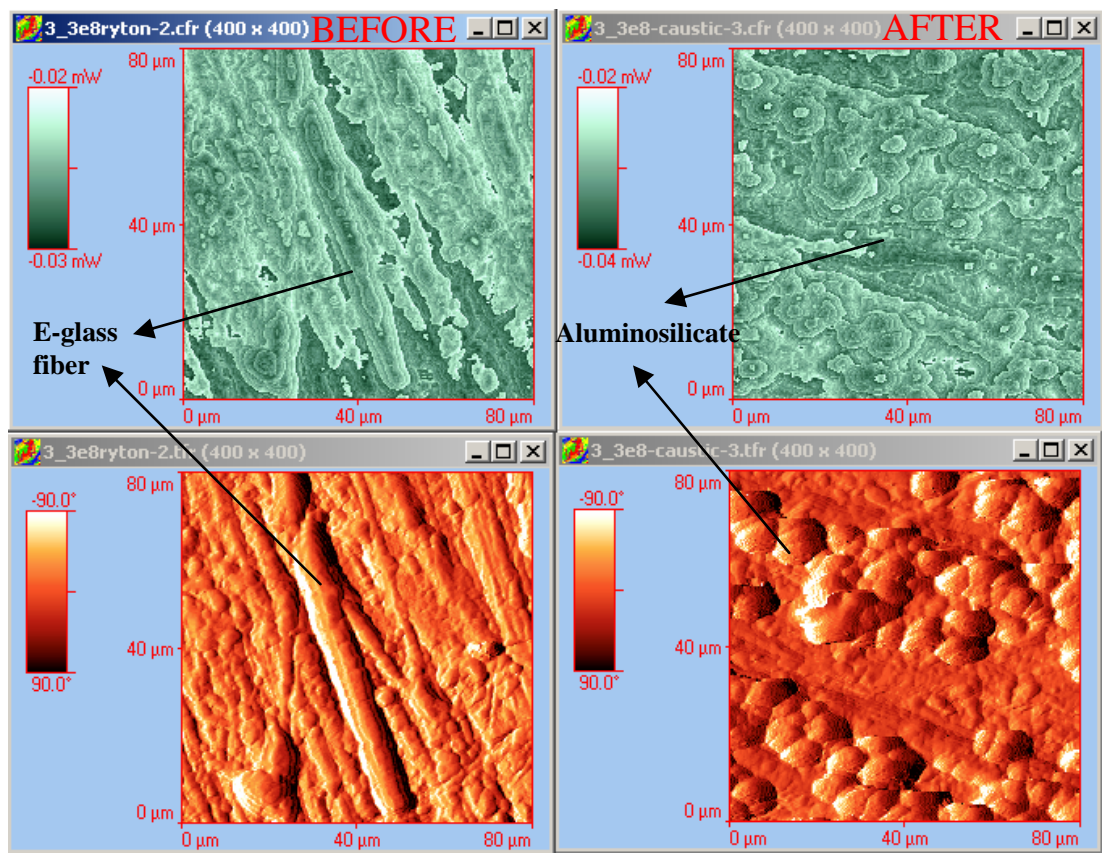

Figure 6. A microthermal analysis of the E-glass/Ryton ${ }^{\mathrm{TM}}$ composite before (left) and after (right) exposure to salt solution containing aluminum. Thermal conductivity (top) and topography (bottom) are shown.

Proof that a film of aluminosilicate formed on the sample shown in Fig. 5 is shown in Fig. 7 where the 100 and 300 microns of material was peeled off from the composite sample in Fig. 5. As can be seen from Fig. 7, the FTIR spectrum show the signal from the aluminosilicate disappeared when 300 microns of material was peeled from the sample thus proving that a finite film of aluminosilicate formed on the sample exposed to caustic solution containing aluminum.

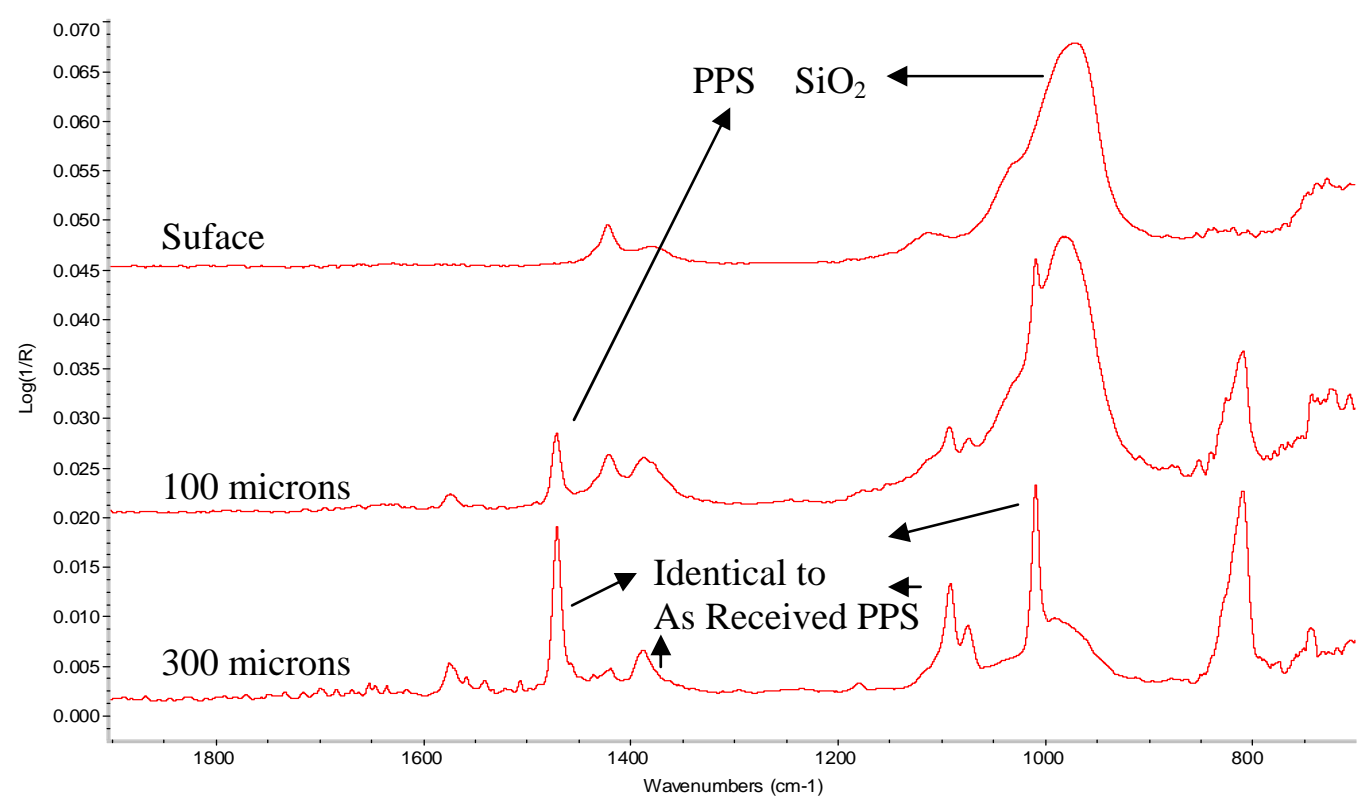

Figure 7. FTIR of the surface of E-glass/PPS after shaving off 100 and 300 microns of material from the surface of PPS that was exposed to $1.91 \mathrm{M}[\mathrm{OH}]$ solution containing $0.31 \mathrm{M} \mathrm{AlO}_{2}^{-}$. 
We then investigated the combined effect of exposing a composite sample to both gamma irradiation and exposure to caustic solution containing aluminum. Exposing the sample to two forms of stress may accelerate degradation of the composite. As shown in Figure 8, a complete aluminosilicate deposition on the E-glass/PPS composite surface occurred approximately within 29 days before the gamma irradiation damage on the PPS can be detected (approximately 4.95 E8 rad). A closer look of Figure 8 shows the fingerprint of aluminosilicate (the shoulder peak at approximately $1000 \mathrm{~cm}^{-1}$ in Figure 8) after two days. This aluminosilicate deposition was faster than that observed in Figure 4 based on the aluminosilicate fingerprint shown in Figure 8 at 2 days. Given that everything was the same (conditions and material used) except for the presence of gamma irradiation, it is possible that gamma irradiation facilitated the rapid nucleation of aluminosilicates on the surface of the E-glass/PPS composite by either changing the solution composition near the surface or by changing the surface itself enough to facilitate rapid heterogeneous nucleation.

In contrast, the aluminosilicate deposition simply masked the signal from the PPS as shown in the symmetry (mirror image) between the two curves in Figure 9. Since no discernible damage to the PPS was seen (of the type seen in Figure 1) before 4.95 E8 rad were irradiated, there is no evidence of significant synergistic effect between gamma irradiation and caustic exposure on the chemical stability of PPS in the E-glass/PPS composite. As can be seen in Figure 9, the surface of the E-glass/PPS composite is completely covered with aluminosilicate after irradiating the sample to 4.95 E8 rad. 


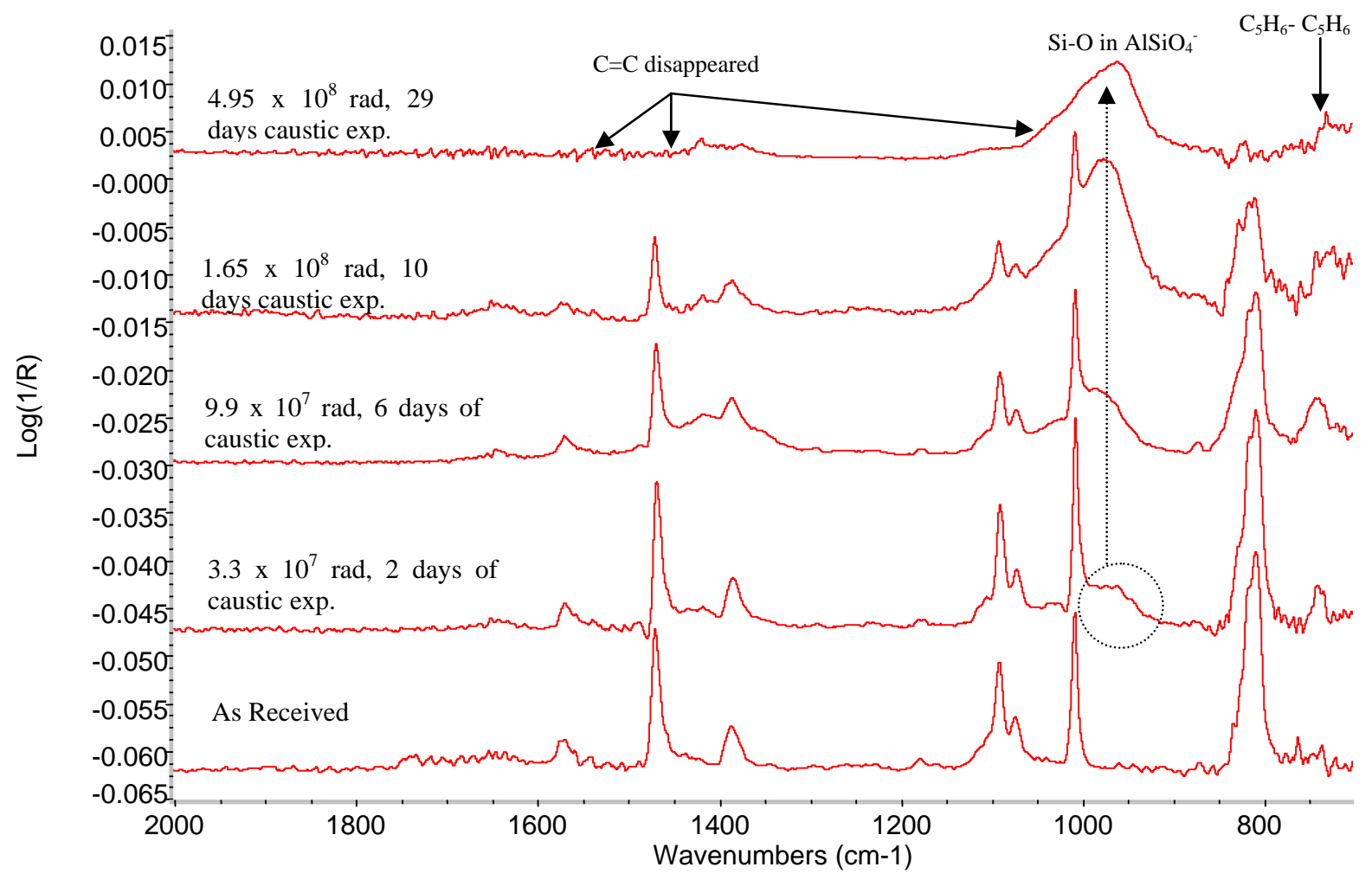

Figure 8. FTIR of the surface of E-glass/PPS after exposure to caustic solution and under gamma irradiation (combined effect).

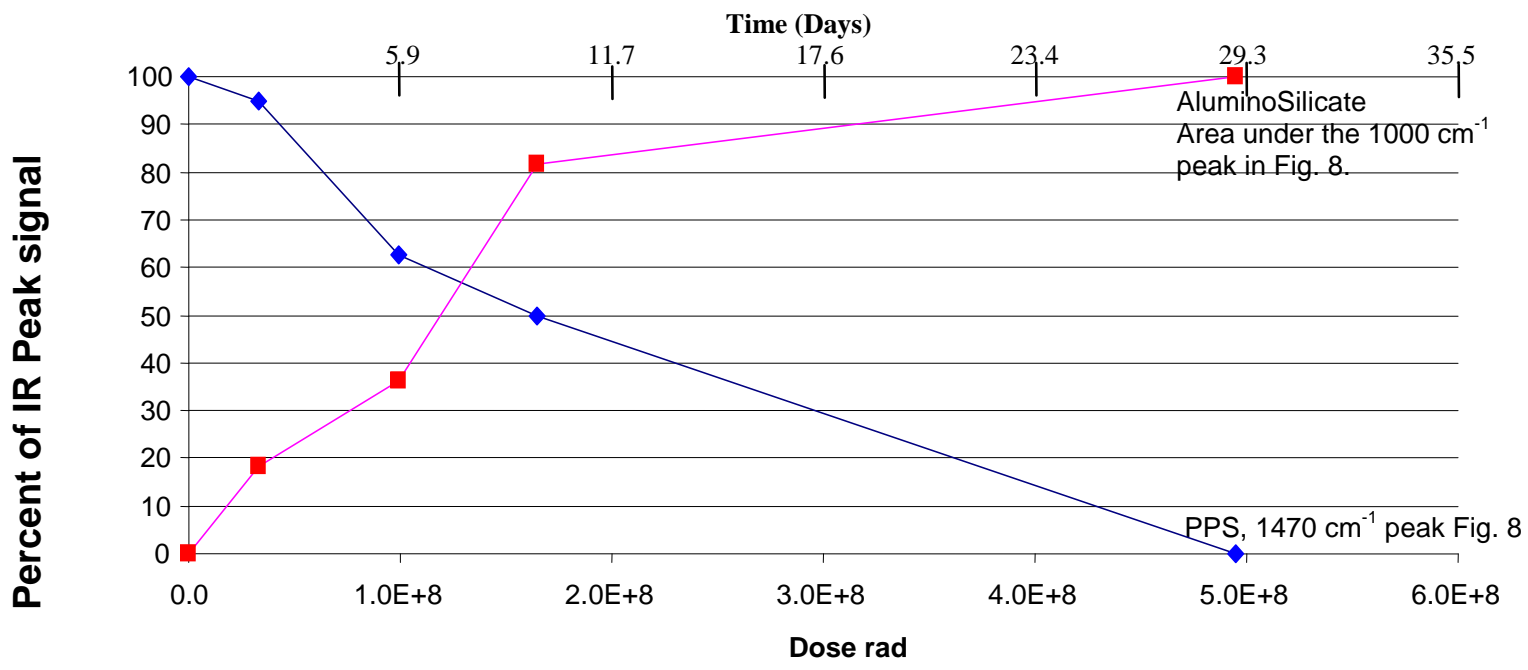

Figure 9. A summary of the peak area of the FTIR data in Figure 8 showing the lifetime of E-glass/PPS (its surface) in a caustic solution containing aluminum and under gamma irradiation for 29 days (= 4.95 E 8 rad / 7.11 E 5 rad per hour). 
Nonwoven Fiber Shaped PPS

Since 2008, the Savannah River Site has utilized nonwoven PPS fibers (in a cartridge form) as a coalescing media for oil in water dispersion. During that time, PPS fibers have been exposed to both gamma irradiation (in some cases up to $7.5 \mathrm{Ci}$ per gallons) and exposure to caustic salt solution containing aluminum as well as to dilute nitric acid (1 mM).

Optical and FTIR analysis of those aged cartridges have revealed that PPS is extremely resilient to gamma irradiation and that heterogeneous nucleation, such as aluminosilicate and Gibbsite deposition, dominates the loss in PPS performance. As shown in Figure 10 and 11, the deposition of aluminosilicate is clear and occurs well before PPS degradation induced by irradiation. In the same process, PPS is exposed to mixtures of alkanes and fluorinated alcohols, none of which reacts with the polymer but some sorption may occur on PPS. The sorption is not irreversible since sorbed CSSX organics were easily removed from PPS with dichloromethane.

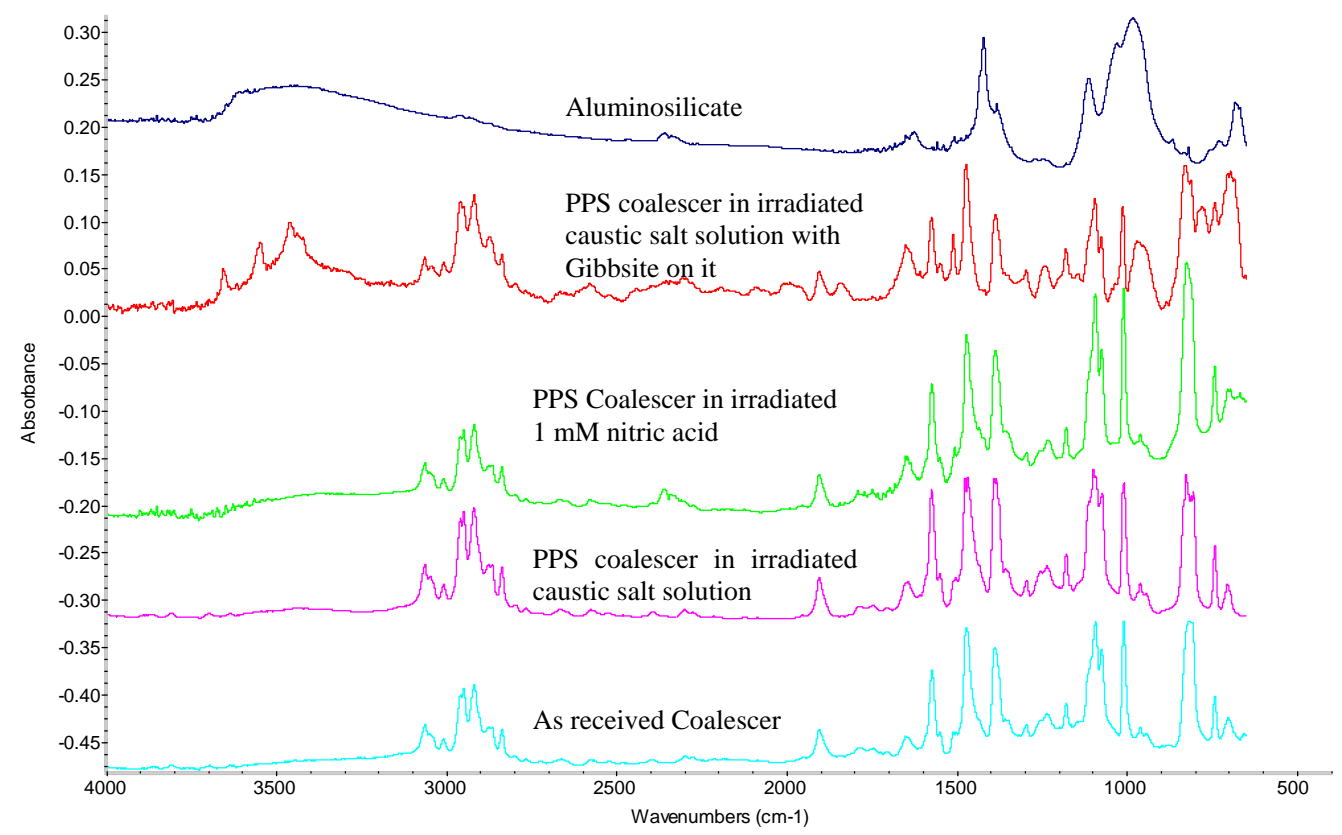

Figure 10. The FTIR of nonwoven PPS that was exposed to $1 \mathrm{mM}$ nitric carrying approximately $1 \mathrm{Ci} /$ gallon for approximately 5 months. 


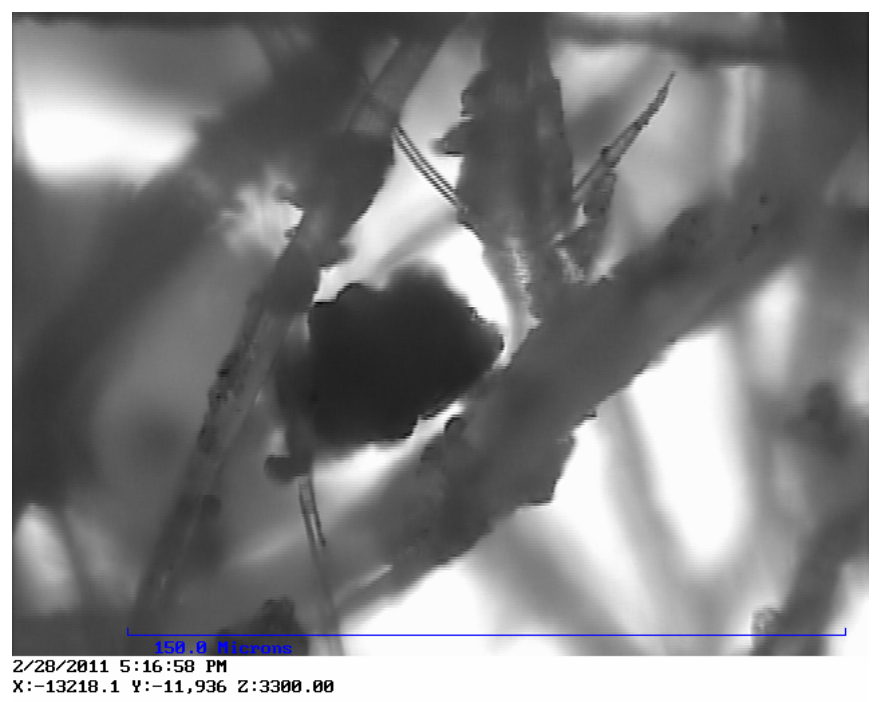

Figure 11. Aluminosilicate formation and trapping of other particles in the nonwoven PPS cartridge that was exposed to salt solution for approximately 6 months (20 $\mathrm{X}$ : Scale bar should read 37.5 microns).

\subsection{Conclusions}

PPS is extremely resistant to gamma irradiation, caustic solution, and dilute nitric acid. PPS is the material of construction for the coalescers used in the Modular Caustic-Side Solvent Extraction Unit (MCU). After applying the equivalent of 3.3 E8 rad gamma irradiation - or the equivalent of 11 years of gamma irradiation (assuming a stripping solution concentration of 7.5 $\mathrm{Ci} /$ gal) - and several months of exposures to caustic solution, no dimensional changes nor chemical changes were detected in PPS whether the PPS was in fiber form or in a composite with E-glass fibers.

However, PPS acts as a media for heterogeneous nucleation. In particular, PPS appears to favor aluminosilicate formation in saturated solutions of aluminum and silicon in caustic environments.

Parallel testing, in progress, is examining the stability of PPS when exposed to the new solvent formulation under development for MCU. Preliminary data from two months of exposure indicates that PPS is stable in the presence of the new next generation solvent. A future report will detail this work. 


\subsection{References}

${ }^{1}$ J. T. Edmonds and H. W. Hill, "U.S. Patent 3354129” 1967.

${ }^{2}$ E. TSuchida, F. Suzuki, E. Shouji, and K. Yamamoto, "Synthesis of PPS by oxidative $\mathrm{O}_{2}$ oxidative polymerization of methyl phenyl sulfide,” Macromolecules (1994), 27, 1057-1060.

${ }^{3}$ J. E. Spruiell and C. E. Janke, "A review of the measurement and development of crystallinity and its relation to properties in neat Polyphenyle sulfide and its fiber reinforced composite," ORNL/TM-2002/304, August 2004.

${ }^{4}$ M. R. Rizzati, M. A. Araujo, and R. P. Livi, "The fluence effect of $\mathrm{Ar}^{2+}$ on PPS,” Nuclear Instruments and Methods in Physics Research B 174 (2001) 475-481.

${ }^{5}$ A. Das, S. Bera, S. Dhara, and A. Patnaik, "Physical and chemical implications of $100 \mathrm{keV} \mathrm{H}^{+}$ implantation of laser ablated PPS thin films," Nuclear Instruments and Methods in Physics Research B 134 (1998) 377-384.

${ }^{6}$ L. S. Farenzena, R. M. Papaleo, A. Hallen, M. A. de Araujo, R. P. Livi, and B. U. R. Sundqvist, "Modifications in the chemical bonding and optical adsorption of PPS by ion bombardment," Nuclear Instruments and Methods in Physics Research B 105 (1995) 134-138.

${ }^{7}$ H. Yamaoka and K. Miyata, “ Radiation effects on organic insulator films at low temperature,” Journal of Nuclear Materials, 133\&134(1985) 788-790

${ }^{8}$ A. Das and A. Patnaik, "The response of pristine and doped poly(p-phenylene sulfide) towards $\mathrm{MeV}$ gamma photons,” Radiation Physics and Chemistry 54 (1999) 109-112

9 "Radiological Health Handbook," U. S. Department of Health, Education, and Welfare, Public Health Service, January 1970. 


\section{Distribution:}
A.B. Barnes, 999-W
D.A. Crowley, 773-43A
R.E. Edwards, 773-67A
T.L. Fellinger, 704-26S
S.D. Fink, 773-A
B.J. Giddings, 786-5A
B.A. Gifford, 704-56H
C.C. Herman, 999-W
D.H. McKenzie, 241-197H
S. L. Marra, 773-A
B.A. Oard, 241-197H
J. E. Occhipinti, 704-S
F.M. Pennebaker, 773-42
T.B. Peters, 773-42A
F. F. Fondeur, 773-A
D. T. Herman, 735-11A
M. R. Poirier,773-42A
T. E. Laupa, 704,27S
P. R. Jackson, 703-43A
K.H. Subramanian, 766-H
M.W. Geeting, 241-152H
M. S. Deshpande, 241-121H
S. P. Mcleskey, 241-152H 